\title{
LICHENS, TOMBSTONES, and LICHENOMETRY
}

Have you ever asked yourself how fast lichens grow, or the approximate age of lichens?

To answer these questions we must realize that lichens are a symbiosis of two totally different organisms, a fungus and an algae, unlike vascular plants or fungi, grow very slowly.

The growth rate is not difficult to observe. All we do is finding a common circular species such as Dimaelina oreina (Moonglow lichen), and measure its diameter, then photograph or trace it and note relevant data. Come back a few years later to the same lichen and measure its diameter again. Compare this new measurement with the old one, and you might notice a millimeter or two of growth. This little experiment shows that lichens are very slow growers, with the exception of a few, such as Peltigera (Felt lichen) which can add about 27 $\mathrm{mm}$ per year.

To answer question two we could visit an old rural cemetery with dated and lichen-covered tombstones to calculate, with reasonable accuracy, the length of time it took to colonize a tombstone. One caveat - we must take into consideration the time needed for the first lichens to become established. This methodology, known as lichenometry, has been used to date ancient stone monuments, rock slides or end moraines.

Although most graves have vertical as well as horizontal tombstones, others have but a single horizontal cover often composed of sandstone or cement carbonate, with varying degrees of lichen cover. The photo below shows such a weathered and broken, lichencovered sandstone grave cover. It was found in an old, no longer used, rural cemetery in southern Saskatchewan along a rural gravel route, south of a longgone settlement. The substrata of tombstones is important. Polished marble, because of its smooth surface, does not allow pioneer species to colonize easily, and remains mostly devoid of lichens. Granite or sandstone, due to their rough surfaces, are more suited to lichen colonization.

Although weathering of the grave stone obliterated most of the burial date, it was barely 
legible as "1896". Assuming that colonization took place a few years later, about 1898, we can assume that the approximate age of lichens would be 115 years.

Exposure and moisture, influence lichen growth. Those lichens on an east or west aspect receive less sunlight and retain more moisture through reduced evaporation. East or west slopes often show a greater lichen diversity than those facing south. South-facing slopes are exposed to more solar radiation, and thus have less ability to hold moisture, allowing at best a scanty lichen growth. Exposure and moisture influences must therefore be taken into account when extrapolating the growth rate of a lichen on one dated tombstone to another situation.

The grave stone in the photo below did not have a great diversity of lichen species - only about eight.
The predominant lobate species was the common pale orange Caloplaca trachyphyla (Desert firedot lichen), with some scattered sub-foliose Xanthoria elegans (Elegant sunburst lichen), and the greenish-yellow, lobate to crustose Dimelaena oreina (Golden moonglow lichen), which were identified in situ. The other lichens occurred as scattered crustose species, well imbedded in the substratum and only removed by chipping, which for obvious reasons is not allowed in cemeteries.

When on your next field outing you happen to be near an old rural cemetery, you can measure some of the lichens on dated tombstones, and figure out their growth rate. Then you will have a simple method for dating other lichen-covered rocks in your area.

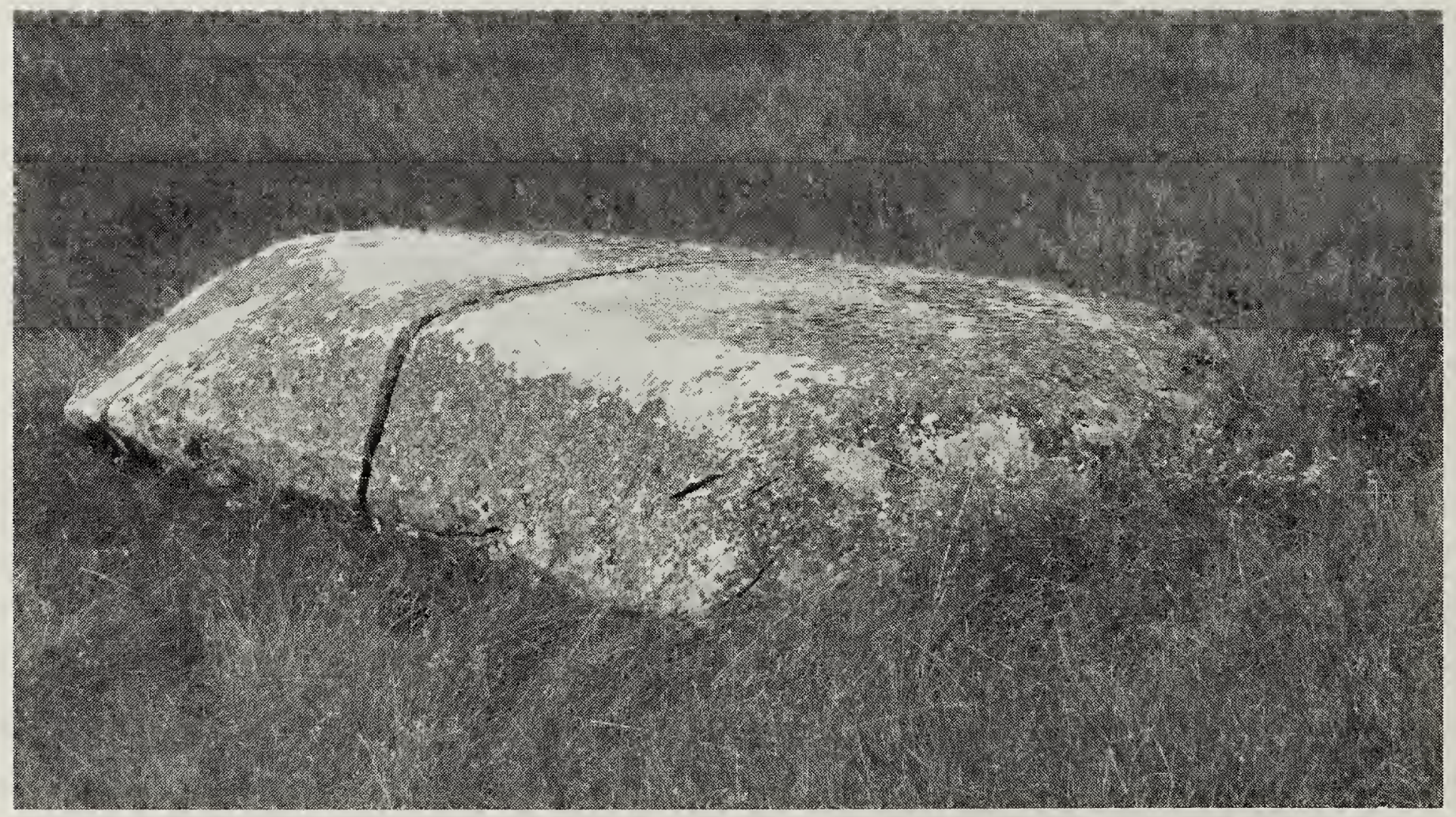

